\title{
Will the age of peak ultra-marathon performance increase with increasing race duration?
}

\author{
Christoph Alexander Rüst ${ }^{1}$, Matthias Alexander Zingg ${ }^{1}$, Thomas Rosemann ${ }^{1}$ and Beat Knechtle ${ }^{1,2,3^{*}}$
}

\begin{abstract}
Background: Recent studies found that the athlete's age of the best ultra-marathon performance was higher than the athlete's age of the best marathon performance and it seemed that the athlete's age of peak ultra-marathon performance increased in distance-limited races with rising distance.

Methods: We investigated the athlete's age of peak ultra-marathon performance in the fastest finishers in time-limited ultra-marathons from 6 hrs to $10 \mathrm{~d}$. Running performance and athlete's age of the fastest women and men competing in 6 hrs, 12 hrs, 24 hrs, 48 hrs, 72 hrs, 144 hrs (6 d) and 240 hrs (10 d) were analysed for races held between 1975 and 2012 using analysis of variance and multi-level regression analysis.

Results: The athlete's ages of the ten fastest women ever in 6 hrs, 12 hrs, 24 hrs, 48 hrs, 72 hrs, $6 \mathrm{~d}$ and $10 \mathrm{~d}$ were $41 \pm$ $9,41 \pm 6,42 \pm 5,46 \pm 5,44 \pm 6,42 \pm 4$, and $37 \pm 4 \mathrm{yrs}$, respectively. The athlete's age of the ten fastest women was different between $48 \mathrm{hrs}$ and $10 \mathrm{~d}$. For men, the athlete's ages were $35 \pm 6,37 \pm 9,39 \pm 8,44 \pm 7,48 \pm 3,48 \pm 8$ and $48 \pm 6$ yrs, respectively. The athlete's age of the ten fastest men in 6 hrs and 12 hrs was lower than the athlete's age of the ten fastest men in $72 \mathrm{hrs}, 6 \mathrm{~d}$ and $10 \mathrm{~d}$, respectively.

Conclusion: The athlete's age of peak ultra-marathon performance did not increase with rising race duration in the best ultra-marathoners. For the fastest women ever in time-limited races, the athlete's age was lowest in $10 \mathrm{~d}$ ( $\sim 37 \mathrm{yrs})$ and highest in 48 hrs ( $\sim 6$ yrs). For men, the athlete's age of the fastest ever in 6 hrs ( $\sim 35$ yrs) and 12 hrs ( $\sim 37$ yrs) was lower than the athlete's age of the ten fastest in 72 hrs ( $48 \mathrm{yrs}), 6 \mathrm{~d}$ ( $48 \mathrm{yrs})$ and $10 \mathrm{~d}$ ( $\sim 88 \mathrm{yrs}$ ). The differences in the athlete's age of peak performance between female and male ultra-marathoners for the different race durations need further investigations.
\end{abstract}

Keywords: Master athlete, Female, Male, Ultra-endurance

\section{Background}

Ultra-marathon running is of high popularity [1-3] where an ultra-marathon is defined as any running distance longer than the classical marathon of the $42.195 \mathrm{~km}$ distance [4]. Most frequently, ultra-marathon races are held in distance-limited races in $\mathrm{km}$ from $50 \mathrm{~km}$ to $100 \mathrm{~km}$, in distance-limited races in miles from 50 miles to 100 miles and in time-limited races from $6 \mathrm{hrs}$ to $24 \mathrm{hrs}$ [4].

Recent studies reported the athlete's age of the best marathon [5] and the best ultra-marathon [3,6] performance. For marathoners, Hunter et al. [5] reported that the fastest marathoners competing in the "World Marathon Majors Series' in the last 30 years were at the age of $29.8 \pm 4.2$ yrs

\footnotetext{
* Correspondence: beat.knechtle@hispeed.ch

${ }^{1}$ Institute of Primary Care, University of Zurich, Zurich, Switzerland

${ }^{2}$ Gesundheitszentrum St. Gallen, St. Gallen, Switzerland

Full list of author information is available at the end of the article
}

in women and $28.9 \pm 3.8$ yrs in men. For ultra-marathoners competing in distance-limited races, it seemed that the athlete's age of peak ultra-marathon performance was higher compared to marathoners [5] and it seemed to increase with rising race distance $[3,6]$. For the annual ten fastest women and men competing in all 100-km ultra-marathons held worldwide between 1960 and 2012, the athlete's age of peak ultra-marathon performance remained unchanged at $34.9 \pm 3.2$ and $34.5 \pm 2.5$ yrs, respectively [6]. In $161-\mathrm{km}$ ultra-marathoners, however, the age of the fastest athletes was higher [3] compared to the age of the fastest 100-km ultra-marathoners [6]. The mean athlete's age of the annual top ten women and men competing between 1998 and 2011 in 161-km ultra-marathons was $39.2 \pm 6.2$ and $37.2 \pm$ $6.1 \mathrm{yrs}$, respectively [3]. The athlete's age of peak ultramarathon performance was not different between women 


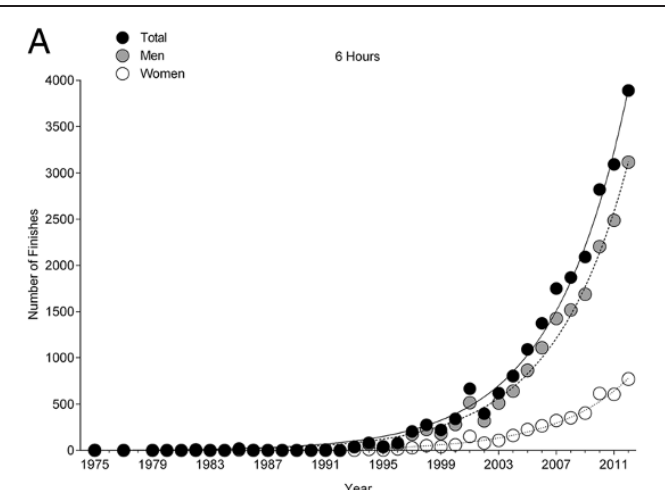

Year
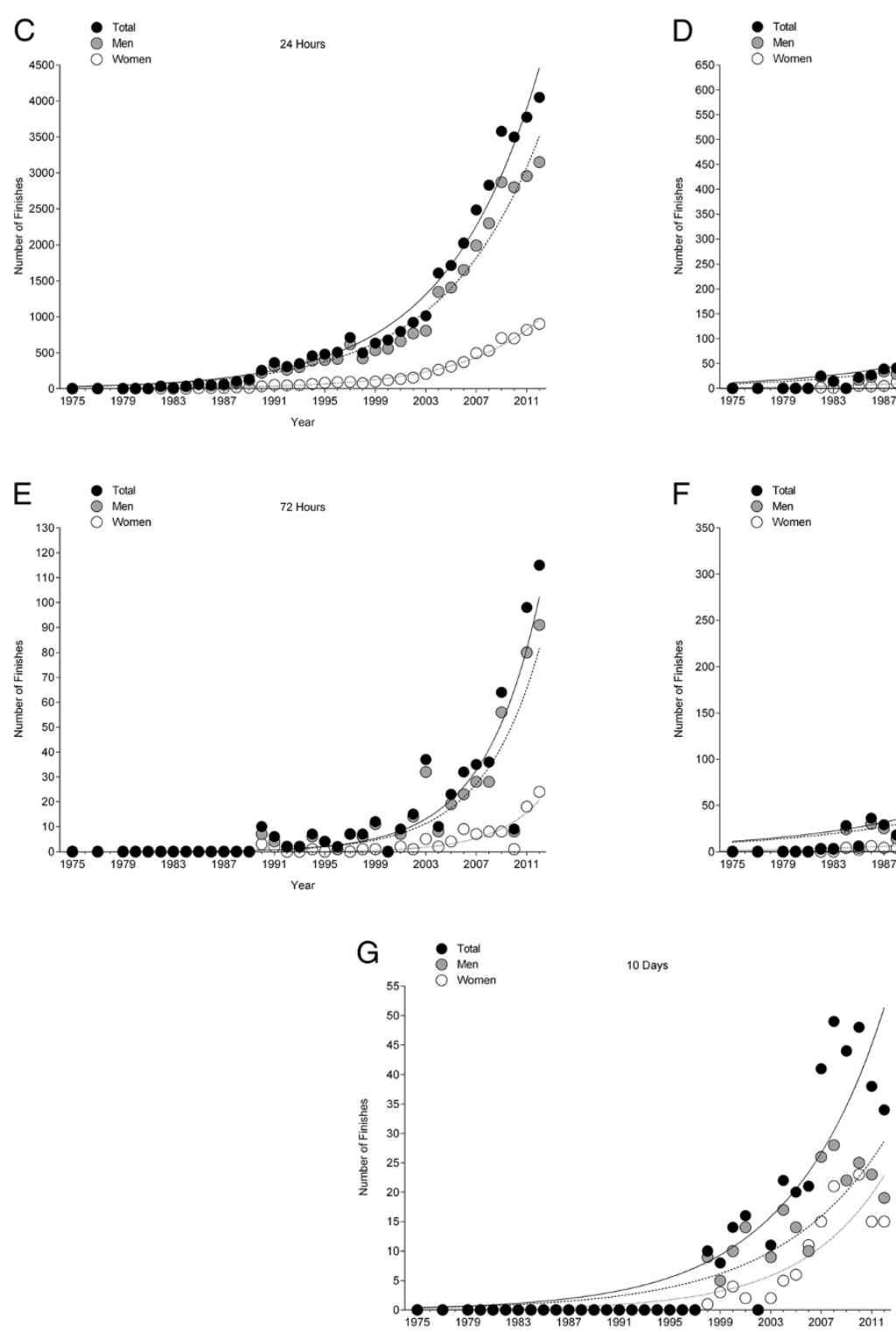

Year
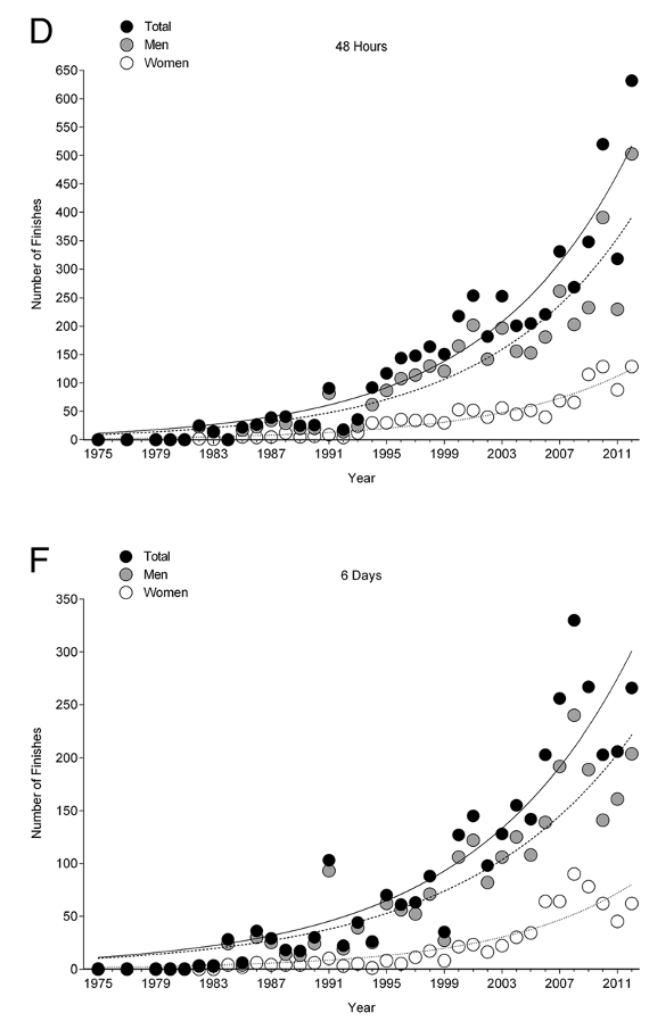

Figure 1 Changes in the numbers of finishes across the years in 6 hrs (Panel A), 12 hrs (Panel B), 24 hrs (Panel C), 48 hrs (Panel D), 72 hrs (Panel E), $6 \mathrm{~d}$ (Panel F) and $10 \mathrm{~d}$ (Panel G).

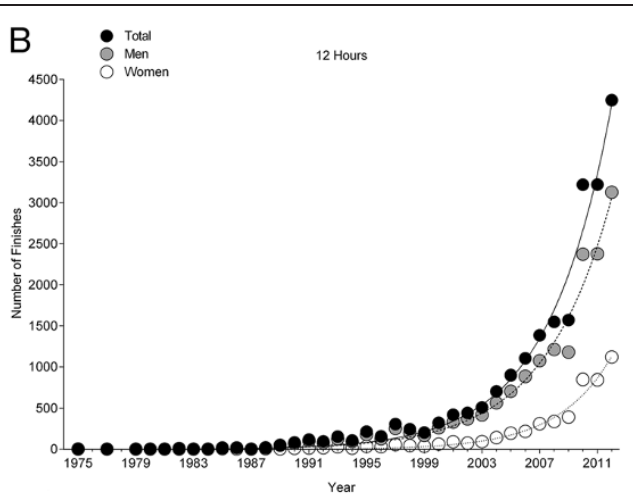




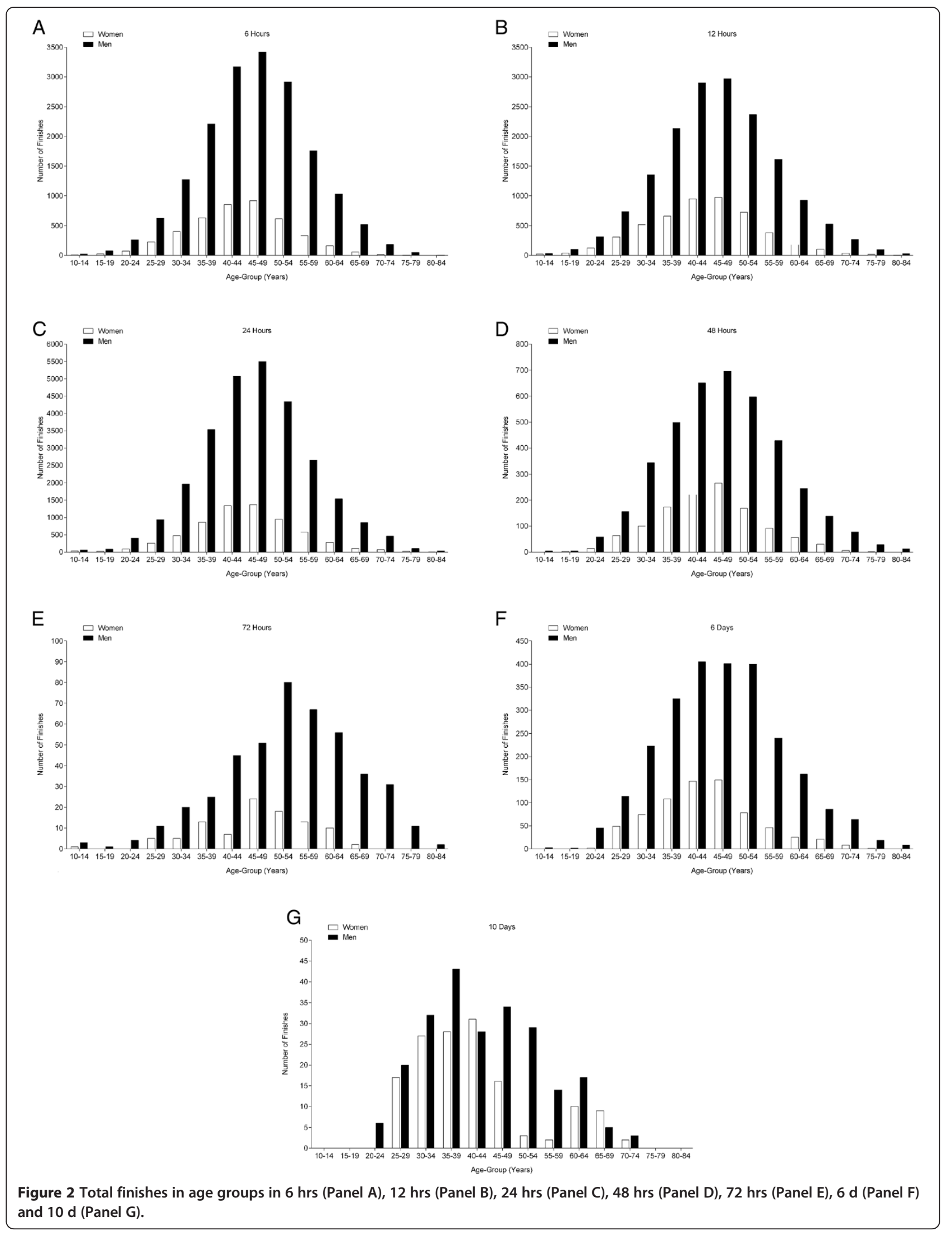


and men and showed no changes across years of competition [3].

For ultra-marathoners, the athlete's age of peak ultramarathon performance has been investigated for single races $[7,8]$ or single distances $[3,9,10]$. However, the assumption that the athlete's age of peak ultra-marathon performance will increase with rising distance or ascending duration of a race needs verification. A very recent study investigating distance-limited ultra-marathons from 50 to 3,100 miles found for men that the age of peak running speed increased with increasing race distance to $\sim 45 \mathrm{yrs}$ in 1,000 miles, whereas it decreased to $\sim 39$ yrs in 3,100 miles. In women, the upper age of peak running speed increased to $\sim 51$ years in 3,100-miles [11]. However, this study lacked the direct comparison between the ages of the fastest runners for each distance and the conclusion that runners in their forties dominate ultra-marathons from 50 to 3,100 miles was based upon approximate comparisons but not statistical analyses [11].

Apart from distance-limited races, also time-limited races do exist [12]. Distance- and time-limited ultra-marathons are basically different since athletes in a distance-limited race have to finish within the time limit whereas athletes in a time-limited race have to cover as many $\mathrm{km}$ as possible within a defined time [12]. However, there is a difference in the number of the most often offered time- and distancelimited races. While there are eight different race durations in the time-limited races (i.e. $6 \mathrm{hrs}, 12 \mathrm{hrs}, 24 \mathrm{hrs}, 48 \mathrm{hrs}$, $72 \mathrm{hrs}, 6 \mathrm{~d}$ and $10 \mathrm{~d}$, there are nine different race distances in the distance-limited races (i.e. $50 \mathrm{~km}, 100 \mathrm{~km}, 200 \mathrm{~km}$, $1,000 \mathrm{~km}, 50$ miles, 100 miles, 200 miles, 1,000 miles and 3,100 miles).

Therefore, the assumption that the age of peak ultramarathon performance increases with increasing race distance [11] must be verified. The first aim of the study was to determine the athlete's age of peak ultra-marathon performance in time-limited races from 6 hrs to $10 \mathrm{~d}$ during the 1975-2012 period and it was hypothesized that the athlete's age of peak ultra-marathon performance would increase with rising duration of the events. Since most of the athletes competing in time-limited ultra-marathons were starting in the shorter distances (i.e. 50 and 100 miles)

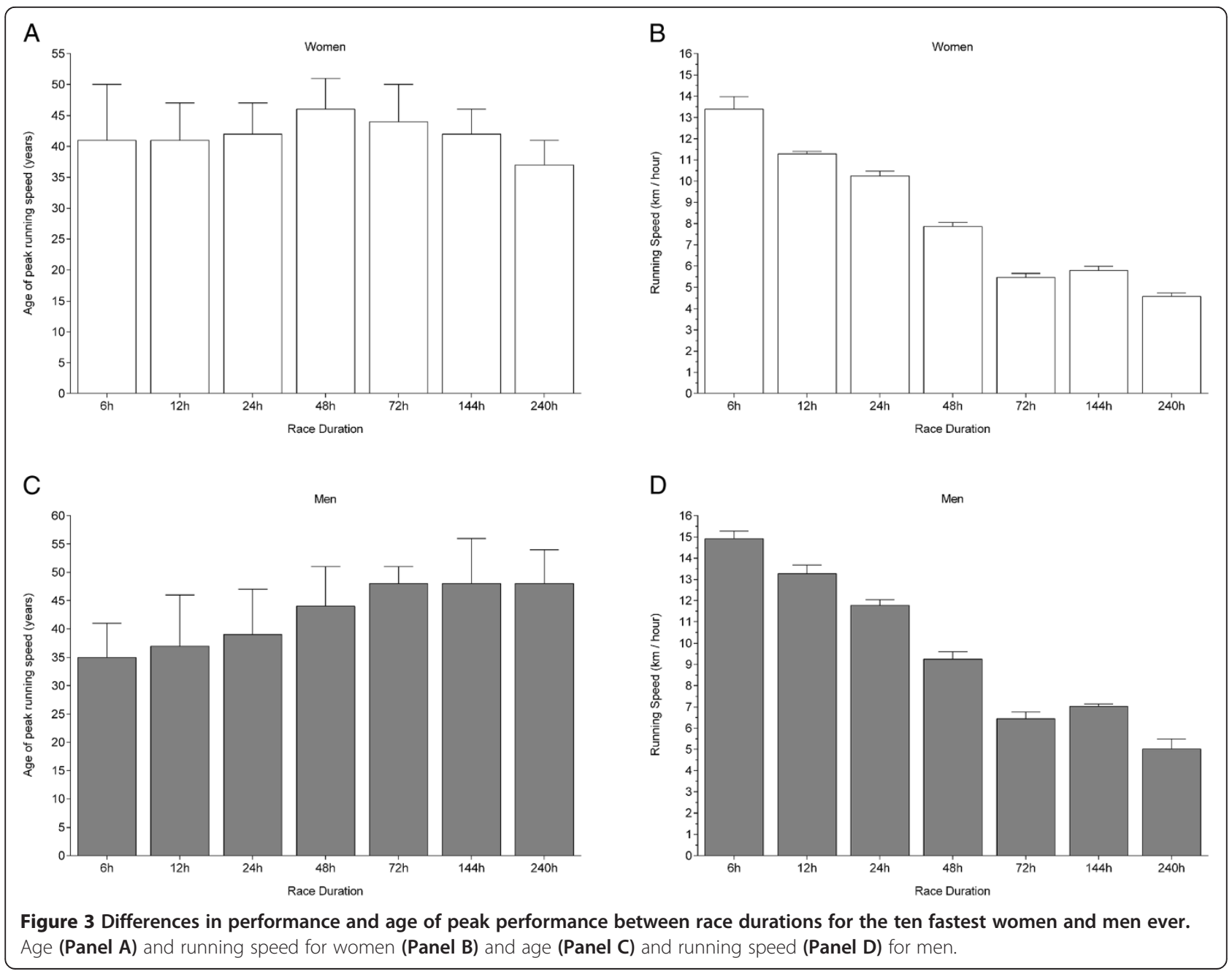


and only a small number of athletes competed in longer distances (i.e. 200 to 3,100 miles) [11], we also analysed the participation trends for the time-limited races.

\section{Methods \\ Ethics}

The study was approved by the Institutional Review Board of St. Gallen, Switzerland, with a waiver of the requirement for informed consent given that the study involved the analysis of publicly available data.

\section{Data sampling and data analysis}

Data were retrieved from the website of Deutsche Ultramarathon Vereinigung (DUV) www.ultra-marathon.org [13]. This website records in the section statistics [14] all race results of ultra-marathons held worldwide. Race results of ultra-marathons held between 1975 and 2012 in timelimited races such 6 hrs, 12 hrs, 24 hrs, 48 hrs, 72 hrs, 144 hrs $(6 \mathrm{~d})$ and 240 hrs $(10 \mathrm{~d})$ were collected. Performances of the annual top and the annual top ten women and men were determined. Additionally, the performances of the ten fastest women and men ever for each race were determined. To allow the comparability between the different race times of $6 \mathrm{hrs}$ and $10 \mathrm{~d}$, all achieved distances $(\mathrm{km})$ were converted to running speed $(\mathrm{km} / \mathrm{h})$ using the equation [running speed $(\mathrm{km} / \mathrm{h})]=[$ race distance $(\mathrm{km})] /[$ race time (h)]. If less than ten athletes were available in a certain year for a certain race time, that year and all race times was excluded from analysis.

\section{Statistical analysis}

Each set of data was tested for normal distribution and for homogeneity of variances prior to statistical analyses. Normal distribution was tested using a D'Agostino and Pearson omnibus normality test and homogeneity of variances was tested using a Levene's test. Trends in participation were analysed using regression analysis with 'straight line' and 'exponential growth equation' model, whereas for each set of data (e.g. each sex) both models where compared using Akaike's Information Criteria (AICc) to decide which model showed the highest probability of correctness. Differences in performance and athlete's age of peak performance between race durations were investigated using one-way analysis of variance (ANOVA) with subsequent Tukey-Kramer post-hoc analysis. To investigate changes in performance and in athlete's age across years of competition, single and multi-level regression analyses were used. A hierarchical regression model was used to avoid the impact of a cluster-effect on results in case one athlete finished more than once in the annual top or top ten. Regression analyses of performance were corrected for the age of the athletes to prevent a misinterpretation of an 'age-effect' as a 'time-effect'. Statistical analyses were performed using IBM
SPSS Statistics (Version 21, IBM SPSS, Chicago, IL, USA) and GraphPad Prism (Version 6.01, GraphPad Software, La Jolla, CA, USA). Significance was accepted at $p<0.05$ (twosided for $t$-tests). Data in the text are given as mean \pm standard deviation (SD).

\section{Results}

Data from 86,451 runners (i.e. 17,901 women and 68,550 men) were available. A total of 1,502 women and 5,099 men had to be excluded from data analysis due to missing information on age in the race results. Overall, data from 16,399 women and 63,451 men were complete and included in the data analysis.

\section{Participation trends}

For all events from 6 hrs to $10 \mathrm{~d}$, an exponential increase in participation was found in both women and men (Figure 1). The number of all events held was highest in $12 \mathrm{hrs}$ but most of the finishes were recorded in $24 \mathrm{hrs}$ for both women and men. In 6 hrs to $48 \mathrm{hrs}$, the highest number of athletes was recorded in age group 45-49 yrs for both

\section{Table 1 Results of the ANOVA for differences in performance and age of peak performance between race durations}

\begin{tabular}{|c|c|c|c|c|}
\hline \multirow[t]{2}{*}{ Comparisons } & \multicolumn{2}{|l|}{ Age } & \multicolumn{2}{|c|}{ Running speed } \\
\hline & Women & Men & Women & Men \\
\hline $6 \mathrm{hrs}$ versus $12 \mathrm{hrs}$ & ns & ns & $* * * *$ & $* * * *$ \\
\hline 6 hrs versus 24 hrs & ns & ns & $* * * *$ & $* * * *$ \\
\hline 6 hrs versus 48 hrs & ns & ns & $* * * *$ & $* * * *$ \\
\hline 6 hrs versus 72 hrs & ns & $* *$ & $* * * *$ & $* * * *$ \\
\hline 6 hrs versus 144 hrs & ns & $* *$ & $* * * *$ & $* * * *$ \\
\hline 6 hrs versus 240 hrs & ns & $* *$ & $* * * *$ & $* * * *$ \\
\hline 12 hrs versus 24 hrs & ns & ns & $* * * *$ & $* * * *$ \\
\hline 12 hrs versus 48 hrs & ns & ns & $* * * *$ & $* * * *$ \\
\hline 12 hrs versus 72 hrs & ns & * & $* * * *$ & $* * * *$ \\
\hline $12 \mathrm{hrs}$ versus $144 \mathrm{hrs}$ & ns & * & $* * * *$ & $* * * *$ \\
\hline $12 \mathrm{hrs}$ versus $240 \mathrm{hrs}$ & ns & * & $* * * *$ & $* * * *$ \\
\hline 24 hrs versus 48 hrs & ns & ns & $* * * *$ & $* * * *$ \\
\hline 24 hrs versus 72 hrs & ns & ns & $* * * *$ & $* * * *$ \\
\hline 24 hrs versus 144 hrs & ns & ns & $* * * *$ & $* * * *$ \\
\hline $24 \mathrm{hrs}$ versus $240 \mathrm{hrs}$ & ns & ns & $* * * *$ & $* * * *$ \\
\hline 48 hrs versus 72 hrs & ns & ns & $* * * *$ & $* * * *$ \\
\hline 48 hrs versus 144 hrs & ns & ns & $* * * *$ & $* * * *$ \\
\hline $48 \mathrm{hrs}$ versus $240 \mathrm{hrs}$ & * & ns & $* * * *$ & $* * * *$ \\
\hline 72 hrs versus 144 hrs & ns & ns & ns & $* *$ \\
\hline 72 hrs versus 240 hrs & ns & ns & $* * * *$ & $* * * *$ \\
\hline 144 hrs versus 240 hrs & ns & ns & $* * * *$ & $* * * *$ \\
\hline
\end{tabular}



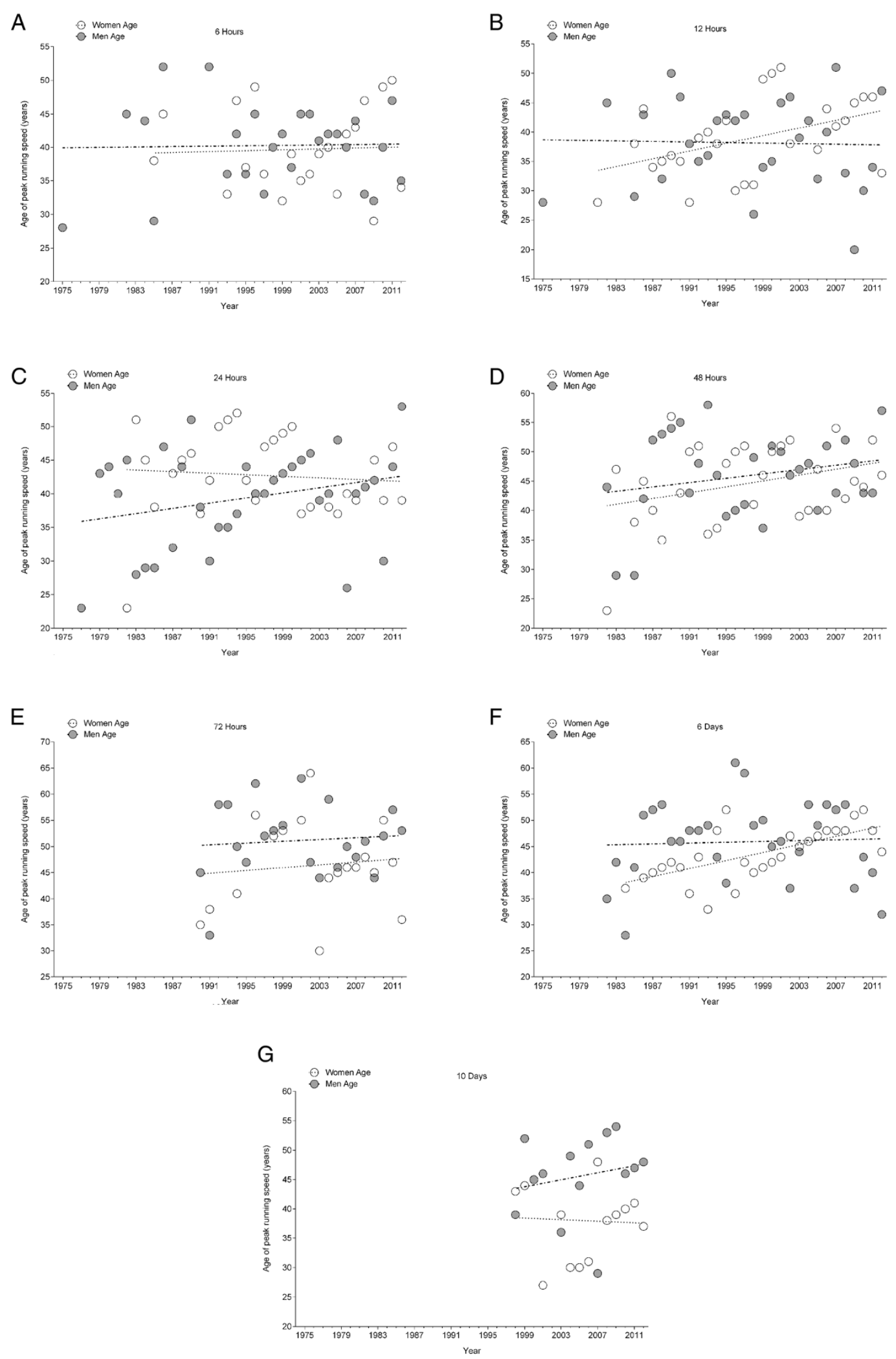

Figure 4 Changes in the age of the annual fastest women and men across the years in 6 hrs (Panel A), 12 hrs (Panel B), 24 hrs (Panel C), 48 hrs (Panel D), 72 hrs (Panel E), 6 d (Panel F) and $10 \mathrm{~d}$ (Panel G). 
Table 2 Multi-level regression analyses for the change in age across years for the annual fastest male and female runners with correction for multiple finishes

\begin{tabular}{|c|c|c|c|c|c|}
\hline & B & SE (ß) & Stand. B & $\mathbf{T}$ & $p$ \\
\hline \multicolumn{6}{|c|}{ Annual fastest men } \\
\hline $6 \mathrm{hrs}$ & 0.015 & 0.130 & 0.023 & 0.114 & 0.910 \\
\hline $12 \mathrm{hrs}$ & -0.023 & 0.155 & -0.029 & -0.151 & 0.881 \\
\hline $24 \mathrm{hrs}$ & 0.193 & 0.118 & 0.275 & 1.642 & 0.110 \\
\hline $48 \mathrm{hrs}$ & 0.184 & 0.147 & 0.229 & 1.248 & 0.223 \\
\hline $72 \mathrm{hrs}$ & 0.084 & 0.222 & 0.084 & 0.377 & 0.710 \\
\hline $6 d$ & 0.039 & 0.154 & 0.047 & 0.252 & 0.803 \\
\hline $10 \mathrm{~d}$ & 0.296 & 0.432 & 0.194 & 0.686 & 0.506 \\
\hline \multicolumn{6}{|c|}{ Annual fastest women } \\
\hline $6 \mathrm{hrs}$ & 0.033 & 0.182 & 0.041 & 0.183 & 0.856 \\
\hline $12 \mathrm{hrs}$ & 0.330 & 0.126 & 0.450 & 2.617 & $0.014^{*}$ \\
\hline $24 \mathrm{hrs}$ & -0.058 & 0.124 & -0.086 & -0.465 & 0.645 \\
\hline $48 \mathrm{hrs}$ & 0.249 & 0.140 & 0.318 & 1.775 & 0.087 \\
\hline $72 \mathrm{hrs}$ & 0.136 & 0.316 & 0.107 & 0.430 & 0.673 \\
\hline $6 \mathrm{~d}$ & 0.385 & 0.083 & 0.666 & 4.640 & $<0.0001^{*}$ \\
\hline $10 \mathrm{~d}$ & -0.067 & 0.401 & -0.048 & -0.166 & 0.871 \\
\hline
\end{tabular}

women and men (Figure 2). For longer race durations, the distribution was different. In $72 \mathrm{hrs}$, the highest number of women was recorded in age group 45-49 yrs and the highest number of men in age group 50-54 yrs. In $6 \mathrm{~d}$, the highest number of athletes was in age group $45-49$ yrs for women and 40-44 yrs for men. For $10 \mathrm{~d}$, the number of recorded athletes was highest in the age group 40-44 yrs for women and 35-39 yrs for men.
Age and running speed of the ten fastest ever

The athlete's age of the ten fastest women ever was $41 \pm 9$ yrs ( $6 \mathrm{hrs}), 41 \pm 6 \mathrm{yrs}$ (12 hrs), $42 \pm 5 \mathrm{yrs}$ ( $24 \mathrm{hrs})$, $46 \pm 5$ yrs ( $48 \mathrm{hrs}), 44 \pm 6$ yrs (72 hrs), $42 \pm 4$ yrs ( $6 \mathrm{~d}$ ), and $37 \pm 4$ yrs $(10 \mathrm{~d})$ (Figure 3 ). The athlete's age of the ten fastest women was different between $48 \mathrm{hrs}$ and $240 \mathrm{hrs}$, no differences were found between the other race durations (Table 1). For men, the athlete's ages were $35 \pm 6$ yrs (6 hrs), $37 \pm 9$ yrs (12 hrs), $39 \pm 8$ yrs ( $24 \mathrm{hrs}), 44 \pm 7$ yrs ( $48 \mathrm{hrs})$, $48 \pm 3$ yrs (72 hrs), $48 \pm 8$ yrs ( $6 \mathrm{~d})$ and $48 \pm 6$ yrs (10 d). The ten fastest men in $6 \mathrm{hrs}$ and $12 \mathrm{hrs}$ were younger than the ten fastest men in $72 \mathrm{hrs}, 6 \mathrm{~d}$ and $10 \mathrm{~d}$, respectively. Running speed was highest in 6 hrs (Figure 3) and decreased with increasing race duration (Table 1) in both women and men.

\section{Age of the annual fastest}

The athlete's age of the annual fastest men (Figure 4) remained unchanged across years of competitions for all events from $6 \mathrm{hrs}$ to $10 \mathrm{~d}$ (Table 2). For women (Figure 4), the athlete's age of the fastest finishers increased in $12 \mathrm{hrs}$ and $6 \mathrm{~d}$ (Table 3) across years of competitions. For the annual ten fastest women and men (Figure 5), the athlete's age of the ten fastest finishers remained unchanged in $6 \mathrm{hrs}$, $12 \mathrm{hrs}, 24 \mathrm{hrs}, 72 \mathrm{hrs}$, and 10 days (Table 4). In $48 \mathrm{hrs}$, the athlete's age of the ten fastest finishers increased for both women and men across years of competitions. In $6 \mathrm{~d}$, the athlete's age of the ten fastest women remained unchanged whereas it increased in men (Table 5).

\section{Running speed of the annual fastest}

The annual fastest men improved running speed in $24 \mathrm{hrs}$ and 72 hrs (Figure 6) across years of competitions, and the

Table 3 Age of the annual fastest finishers in races held between $\mathbf{6}$ hrs and $10 \mathrm{~d}$

\begin{tabular}{|c|c|c|c|c|}
\hline Race & Sex & $\begin{array}{l}\text { Age of the runners at the start } \\
\text { of the investigated period (yrs) }\end{array}$ & $\begin{array}{l}\text { Age of the runners with no } \\
\text { change across years (yrs) }\end{array}$ & $\begin{array}{l}\text { Age of the runners at the end } \\
\text { of the investigated period (yrs) }\end{array}$ \\
\hline \multirow[t]{2}{*}{$6 \mathrm{hrs}$} & Women & & $40 \pm 6$ & \\
\hline & Men & & $40 \pm 6$ & \\
\hline \multirow[t]{2}{*}{$12 \mathrm{hrs}$} & Women & 28 (1975) & & 33 (2012) \\
\hline & Men & & $38 \pm 7$ & \\
\hline \multirow[t]{2}{*}{$24 \mathrm{hrs}$} & Women & & $43 \pm 6$ & \\
\hline & Men & & $39 \pm 7$ & \\
\hline \multirow[t]{2}{*}{$48 \mathrm{hrs}$} & Women & & $45 \pm 7$ & \\
\hline & Men & & $46 \pm 7$ & \\
\hline \multirow[t]{2}{*}{$72 \mathrm{hrs}$} & Women & & $46 \pm 8$ & \\
\hline & Men & & $51 \pm 7$ & \\
\hline \multirow[t]{2}{*}{$6 \mathrm{~d}$} & Women & 37 (1984) & & 44 (2012) \\
\hline & Men & & $46 \pm 7$ & \\
\hline \multirow[t]{2}{*}{$10 \mathrm{~d}$} & Women & & $38 \pm 6$ & \\
\hline & Men & & $46 \pm 7$ & \\
\hline
\end{tabular}


A

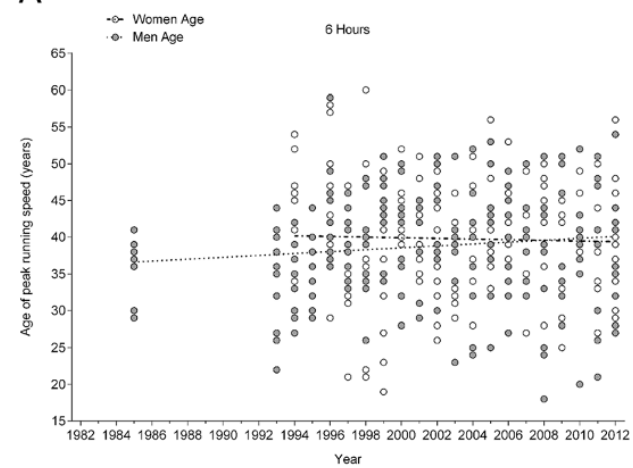

C

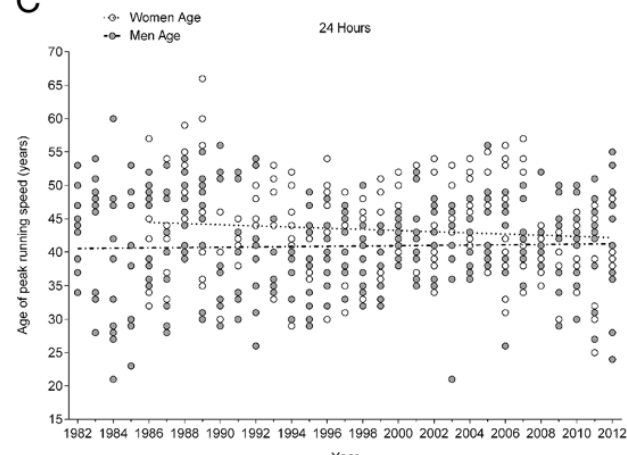

Year

E

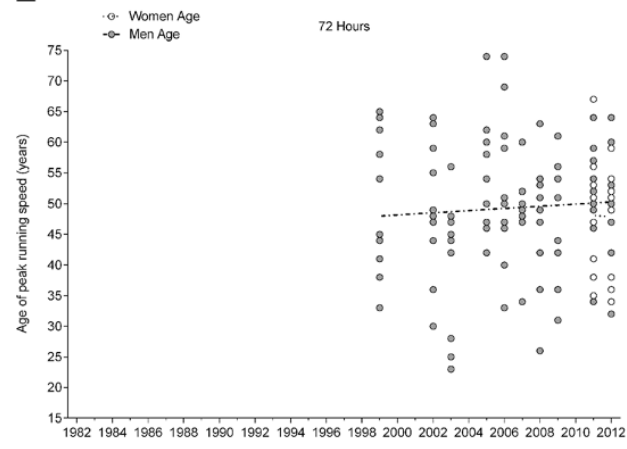

Year
B

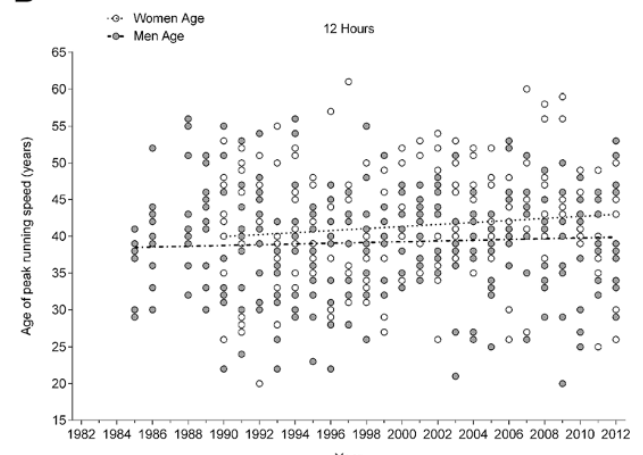

D

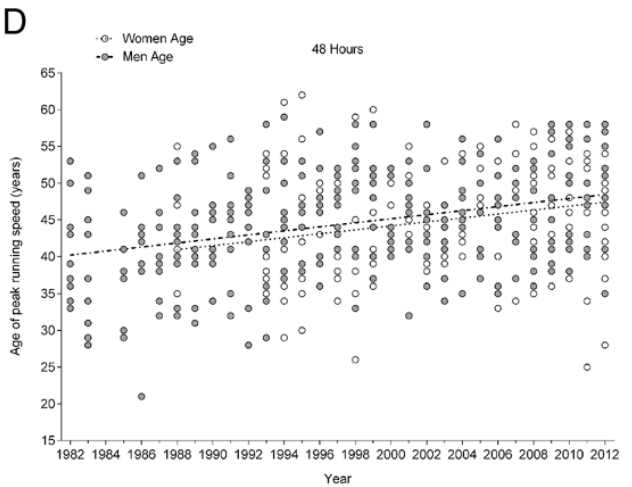

$\mathrm{F}$

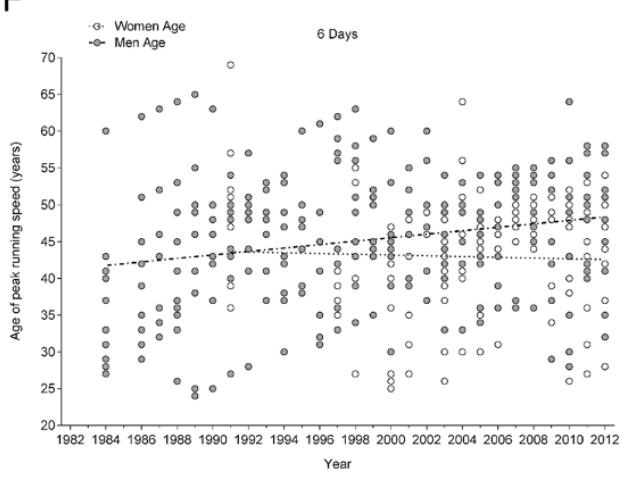

G

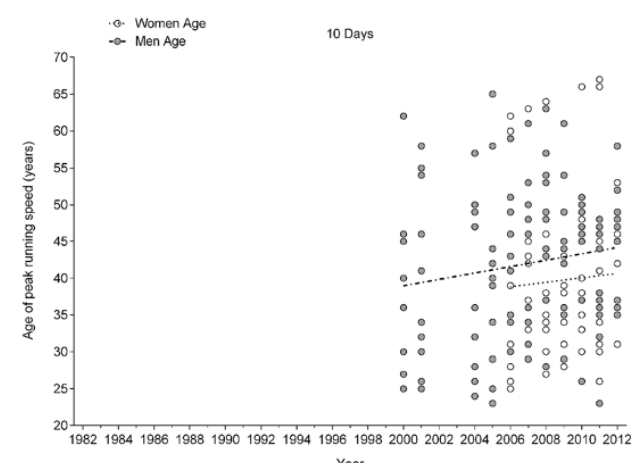

Figure 5 Changes in the age of the annual ten fastest women and men across the years in 6 hrs (Panel A), 12 hrs (Panel B), 24 hrs (Panel C), 48 hrs (Panel D), 72 hrs (Panel E), $6 \mathrm{~d}$ (Panel F) and $10 \mathrm{~d}$ (Panel G). 
Table 4 Multi-level regression analyses for the change in age across years for the annual ten fastest male and female runners after correction for multiple finishes

\begin{tabular}{|c|c|c|c|c|c|}
\hline & $B$ & SE (ß) & Stand. B & $\mathrm{T}$ & $p$ \\
\hline \multicolumn{6}{|c|}{ Annual ten fastest men } \\
\hline $6 \mathrm{hrs}$ & 0.129 & 0.076 & 0.117 & 1.693 & 0.092 \\
\hline $12 \mathrm{hrs}$ & 0.052 & 0.056 & 0.056 & 0.925 & 0.356 \\
\hline 24 hrs & 0.023 & 0.045 & 0.030 & 0.518 & 0.605 \\
\hline 48 hrs & 0.275 & 0.043 & 0.347 & 6.390 & $<0.0001$ * \\
\hline 72 hrs & 0.177 & 0.277 & 0.064 & 0.638 & 0.525 \\
\hline $6 \mathrm{~d}$ & 0.236 & 0.062 & 0.224 & 3.833 & $<0.0001 *$ \\
\hline $10 d$ & 0.435 & 0.262 & 0.158 & 1.658 & $0.100 *$ \\
\hline \multicolumn{6}{|c|}{ Annual ten fastest women } \\
\hline $6 \mathrm{hrs}$ & -0.045 & 0.114 & -0.029 & -0.392 & 0.696 \\
\hline $12 \mathrm{hrs}$ & 0.138 & 0.074 & 0.123 & 1.865 & 0.063 \\
\hline $24 \mathrm{hrs}$ & -0.087 & 0.052 & -0.103 & -1.693 & 0.092 \\
\hline 48 hrs & 0.269 & 0.075 & 0.241 & 3.576 & $<0.0001 *$ \\
\hline 72 hrs & -0.200 & 4.419 & -0.011 & -0.045 & 0.964 \\
\hline $6 \mathrm{~d}$ & -0.052 & 0.114 & -0.036 & -0.454 & 0.650 \\
\hline $10 d$ & 0.304 & 0.651 & 0.056 & 0.466 & 0.642 \\
\hline
\end{tabular}

annual fastest women in all race durations except $72 \mathrm{hrs}$ and $6 \mathrm{~d}$ (Table 6 and 7). The annual ten fastest women and men (Figure 7) improved running speed in race durations (Table 8) with the exception of $6 \mathrm{~d}$ in men where performance decreased (Table 9). Men improved running speed in $6 \mathrm{hrs}$ (19.5\%), $12 \mathrm{hrs}$ (11.8\%), $24 \mathrm{hrs}$ (40.8\%), $48 \mathrm{hrs}$ (17.8\%), 72 hrs (54.0\%), and $10 \mathrm{~d}(16.6 \%)$. In $6 \mathrm{~d}$, performance decreased by $8.4 \%$. Women improved running speed in $6 \mathrm{hrs}$ (28.1\%), $12 \mathrm{hrs}$ (50.4\%), $24 \mathrm{hrs}$ (57.5\%), $48 \mathrm{hrs}$ (13.1\%), 72 hrs (14.4\%), $6 \mathrm{~d}$ (45.6\%), and $10 \mathrm{~d}$ (15.1\%).

\section{Discussion}

This study intended to determine the athlete's age of peak running speed in ultra-marathoners competing in timelimited race held for $6 \mathrm{hrs}, 12 \mathrm{hrs}, 24 \mathrm{hrs}, 48 \mathrm{hrs}, 6 \mathrm{~d}$ and $10 \mathrm{~d}$ between 1975 and 2012 with the hypothesis that the athlete's age of peak ultra-marathon performance would increase with the duration of the event. In contrast to the hypothesis, the athlete's age of peak ultra-marathon performance did not increase with rising race duration.

\section{Differences in the athlete's age of peak performance between women and men}

Regarding the ten fastest women and men ever, the athlete's age of the ten fastest women was different between $48 \mathrm{hrs}$ and $240 \mathrm{hrs}$, but no differences were found between the other race durations. For men, the ten fastest men in $6 \mathrm{hrs}$ and $12 \mathrm{hrs}$ were younger than the ten fastest men in $72 \mathrm{hrs}$, $6 \mathrm{~d}$ and $10 \mathrm{~d}$, respectively. Potential explanations for these sex differences could be $(i)$ differences in participations trends between women and men, (ii) differences between women and man in motivation to compete, and (iii) differences in previous experience between women and men in ultra-marathon running.

Although participation increased in both women and men for all event durations in an exponential manner, female participation was considerably lower compared to men's participation. Generally, women account for $\sim 10$ $20 \%$ in ultra-running competitions [2,3] although female participation increased in recent years in ultra-marathon running across years of competitions $[15,16]$.

\section{Table 5 Age of the annual ten fastest finishers in races held between 6 hrs and $10 \mathrm{~d}$}

\begin{tabular}{|c|c|c|c|c|}
\hline Race & Sex & $\begin{array}{l}\text { Age of the runners at the start } \\
\text { of the investigated period (yrs) }\end{array}$ & $\begin{array}{l}\text { Age of the runners with no } \\
\text { change across years (yrs) }\end{array}$ & $\begin{array}{l}\text { Age of the runners at the end } \\
\text { of the investigated period (yrs) }\end{array}$ \\
\hline \multirow[t]{2}{*}{$6 \mathrm{hrs}$} & Women & & $39.8 \pm 7.7$ & \\
\hline & Men & & $38.8 \pm 7.1$ & \\
\hline \multirow[t]{2}{*}{$12 \mathrm{hrs}$} & Women & & $41.5 \pm 7.5$ & \\
\hline & Men & & $39.2 \pm 7.0$ & \\
\hline \multirow[t]{2}{*}{$24 \mathrm{hrs}$} & Women & & $43.3 \pm 6.2$ & \\
\hline & Men & & $40.9 \pm 6.6$ & \\
\hline \multirow[t]{2}{*}{48 hrs } & Women & $41.2 \pm 6.6(1988)$ & & $43.8 \pm 7.5(2012)$ \\
\hline & Men & $40.3 \pm 7.0(1982)$ & & $50.2 \pm 7.6(2012)$ \\
\hline \multirow[t]{2}{*}{72 hrs } & Women & & $48.0 \pm 9.9$ & \\
\hline & Men & & $49.3 \pm 10.1$ & \\
\hline \multirow[t]{2}{*}{$6 d$} & Women & & $42.9 \pm 6.9$ & \\
\hline & Men & $36.9 \pm 9.9(1984)$ & & $47.7 \pm 9.4(2012)$ \\
\hline \multirow[t]{2}{*}{$10 \mathrm{~d}$} & Women & & $39.7 \pm 10.5$ & \\
\hline & Men & & $41.8 \pm 10.2$ & \\
\hline
\end{tabular}



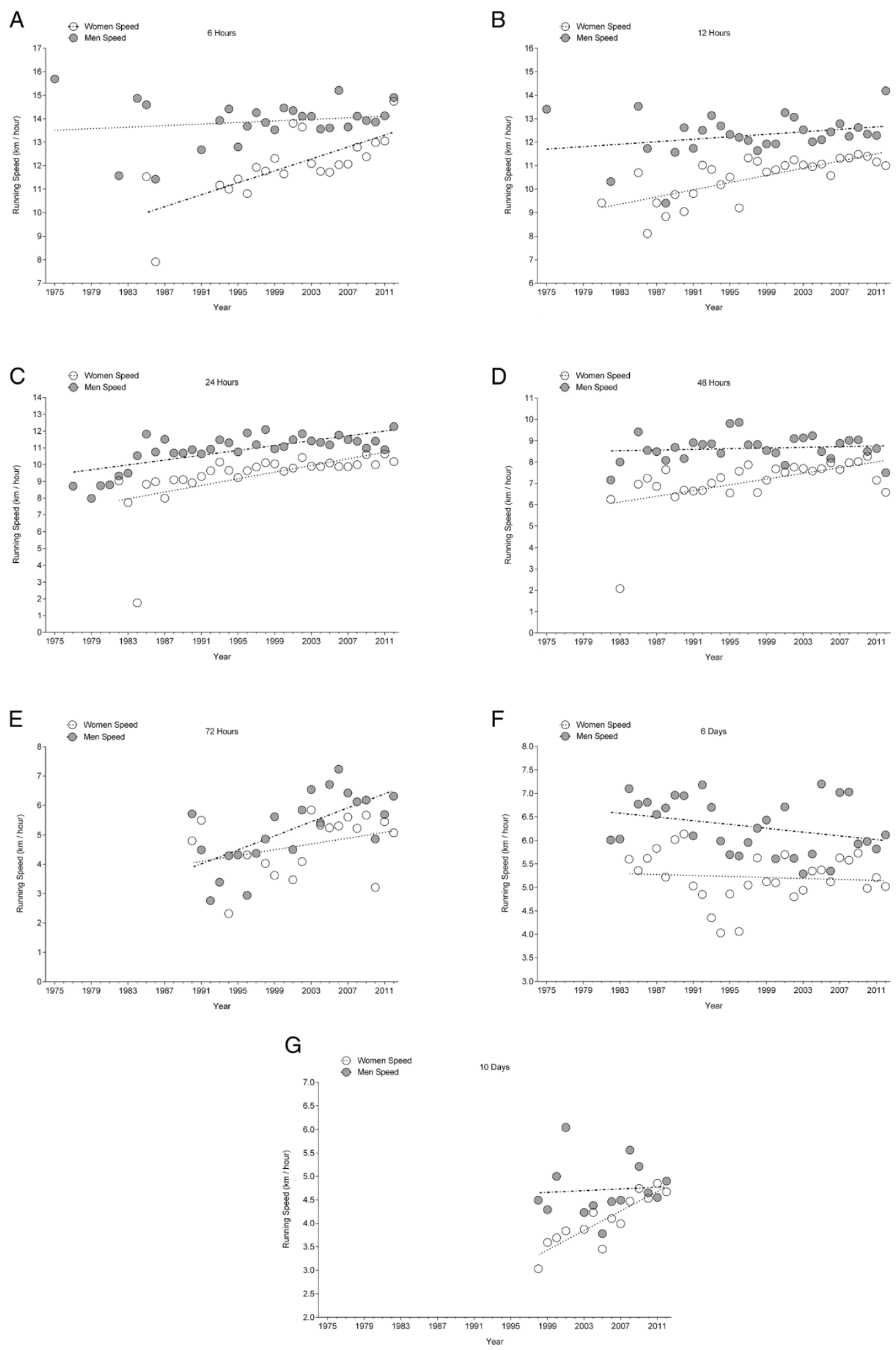

Figure 6 Changes in running speeds of the annual fastest women and men across the years in 6 hrs (Panel A), 12 hrs (Panel B), 24 hrs (Panel C), 48 hrs (Panel D), 72 hrs (Panel E), 6 d (Panel F) and $10 \mathrm{~d}$ (Panel G). 
Table 6 Multi-level regression analyses for change in running speed across years for the annual fastest male and female runners after correction for multiple finishes and age of athletes with multiple finishes

\begin{tabular}{|c|c|c|c|c|c|}
\hline & $B$ & SE (ß) & Stand. B & $\mathrm{T}$ & $p$ \\
\hline \multicolumn{6}{|c|}{ Annual fastest men } \\
\hline $6 \mathrm{hrs}$ & 0.018 & 0.016 & 0.183 & 1.095 & 0.285 \\
\hline $12 \mathrm{hrs}$ & 0.027 & 0.018 & 0.272 & 1.445 & 0.161 \\
\hline 24 hrs & 0.075 & 0.013 & 0.747 & 5.891 & $<0.0001 *$ \\
\hline $48 \mathrm{hrs}$ & 0.013 & 0.012 & 0.193 & 1.036 & 0.310 \\
\hline 72 hrs & 0.126 & 0.023 & 0.712 & 5.443 & $<0.0001 *$ \\
\hline $6 \mathrm{~d}$ & -0.020 & 0.011 & -0.316 & -1.767 & 0.088 \\
\hline $10 \mathrm{~d}$ & 0.001 & 0.037 & 0.009 & 0.030 & 0.977 \\
\hline \multicolumn{6}{|c|}{ Annual fastest women } \\
\hline $6 \mathrm{hrs}$ & 0.129 & 0.026 & 0.730 & 4.959 & $<0.0001 *$ \\
\hline 12 hrs & 0.075 & 0.015 & 0.722 & 4.866 & $<0.0001 *$ \\
\hline 24 hrs & 0.099 & 0.027 & 0.578 & 3.739 & $0.001 *$ \\
\hline 48 hrs & 0.074 & 0.021 & 0.604 & 3.628 & $0.001 *$ \\
\hline 72 hrs & 0.058 & 0.031 & 0.386 & 1.872 & 0.081 \\
\hline $6 \mathrm{~d}$ & 0-.013 & 0.016 & -0.212 & -0.818 & 0.421 \\
\hline $10 \mathrm{~d}$ & 0.104 & 0.017 & 0.883 & 6.248 & $<0.0001 *$ \\
\hline
\end{tabular}

Different motivational factors between women and men might also be a potential reason to explain the differences in the athlete's ages [17-19]. For female ultra-marathoners, task orientation (i.e. finishing an ultra-marathon or accomplishing various goals) was more important than ego orientation (i.e. placing in the top three overall or beating the concurrent) [18]. Generally, men are over-represented in sports and distance running is an ideal domain for male predisposition for enduring competitiveness or long-term motivation to improve one's performance [19]. Distance running indicates enduring competitiveness, allows objective comparisons, and is accessible, acceptable, and popular for both men and women [19]. More men than women run relatively fast in the United States of America which is attributed to men's greater training motivation [19].

The aspect of experience might be important to explain the dominance of master runners in ultra-distances [20,21]. In 161-km ultra-marathons held in North America between 1977 and 2008, the number of annually completed races by an individual athlete increased across years [22]. Successful ultra-marathoners generally train for $\sim 7$ yrs before competing in the first ultra-marathon [21] and have $\sim 7$ yrs of experience in ultra-marathon running [20]. Active ultramarathoners train for $\sim 3,300 \mathrm{~km}$ per year where the annual running distance is related to age and the longest ultramarathon held within that year [23]. Hoffman and Parise [21] showed for 161-km ultra-marathoners that high-level performances can be sustained late into the fourth decade of life but subsequent aging is associated with declines in performance and the adverse effects of aging on performance can be offset by greater experience in these events.

It is a common finding that successful ultra-marathoners are older than 35 yrs [2,8,20,23-25]. Wegelin and Hoffman [26] showed that especially women performed better than men above the age of 38 yrs. Additionally, ultramarathoners seemed to be well-educated middle-aged men since most of the successful 161-km ultra-marathoners have a high education. Hoffman and Fogard [25] reported that $43.6 \%$ of $161-\mathrm{km}$ ultra-marathoners had a bachelor degree and $37.2 \%$ and graduate degree.

Table 7 Running speed of the annual fastest finishers in races held between 6 hrs and $10 \mathrm{~d}$

\begin{tabular}{|c|c|c|c|c|}
\hline Race & Sex & $\begin{array}{l}\text { Running speed of the runners at the } \\
\text { start of the investigated period }(\mathrm{km} / \mathrm{h})\end{array}$ & $\begin{array}{l}\text { Running speed of the runners with } \\
\text { no change across years }(\mathrm{km} / \mathrm{h})\end{array}$ & $\begin{array}{l}\text { Running speed of the runners at the } \\
\text { end of the investigated period }(\mathrm{km} / \mathrm{h})\end{array}$ \\
\hline \multirow[t]{2}{*}{$6 \mathrm{hrs}$} & Women & $11.53(1985)$ & & 14.75 (2012) \\
\hline & Men & & $13.89 \pm 0.96$ & \\
\hline \multirow[t]{2}{*}{$12 \mathrm{hrs}$} & Women & 9.41 (1981) & & 11.0 (2012) \\
\hline & Men & & $12.30 \pm 0.91$ & \\
\hline \multirow[t]{2}{*}{$24 \mathrm{hrs}$} & Women & 9.03 (1982) & & 10.18 (2012) \\
\hline & Men & 8.71 (1977) & & $12.27(2012)$ \\
\hline \multirow[t]{2}{*}{$48 \mathrm{hrs}$} & Women & 6.25 (1982) & & $6.58(2012)$ \\
\hline & Men & & $8.64 \pm 0.59$ & \\
\hline \multirow[t]{2}{*}{$72 \mathrm{hrs}$} & Women & & $4.66 \pm 1.00$ & \\
\hline & Men & 5.71 (1990) & & 6.31 (2012) \\
\hline \multirow[t]{2}{*}{$6 \mathrm{~d}$} & Women & & $5.21 \pm 0.51$ & \\
\hline & Men & & $6.29 \pm 0.57$ & \\
\hline \multirow[t]{2}{*}{$10 \mathrm{~d}$} & Women & 3.03 (1998) & & $4.76(2012)$ \\
\hline & Men & & $4.71 \pm 0.58$ & \\
\hline
\end{tabular}



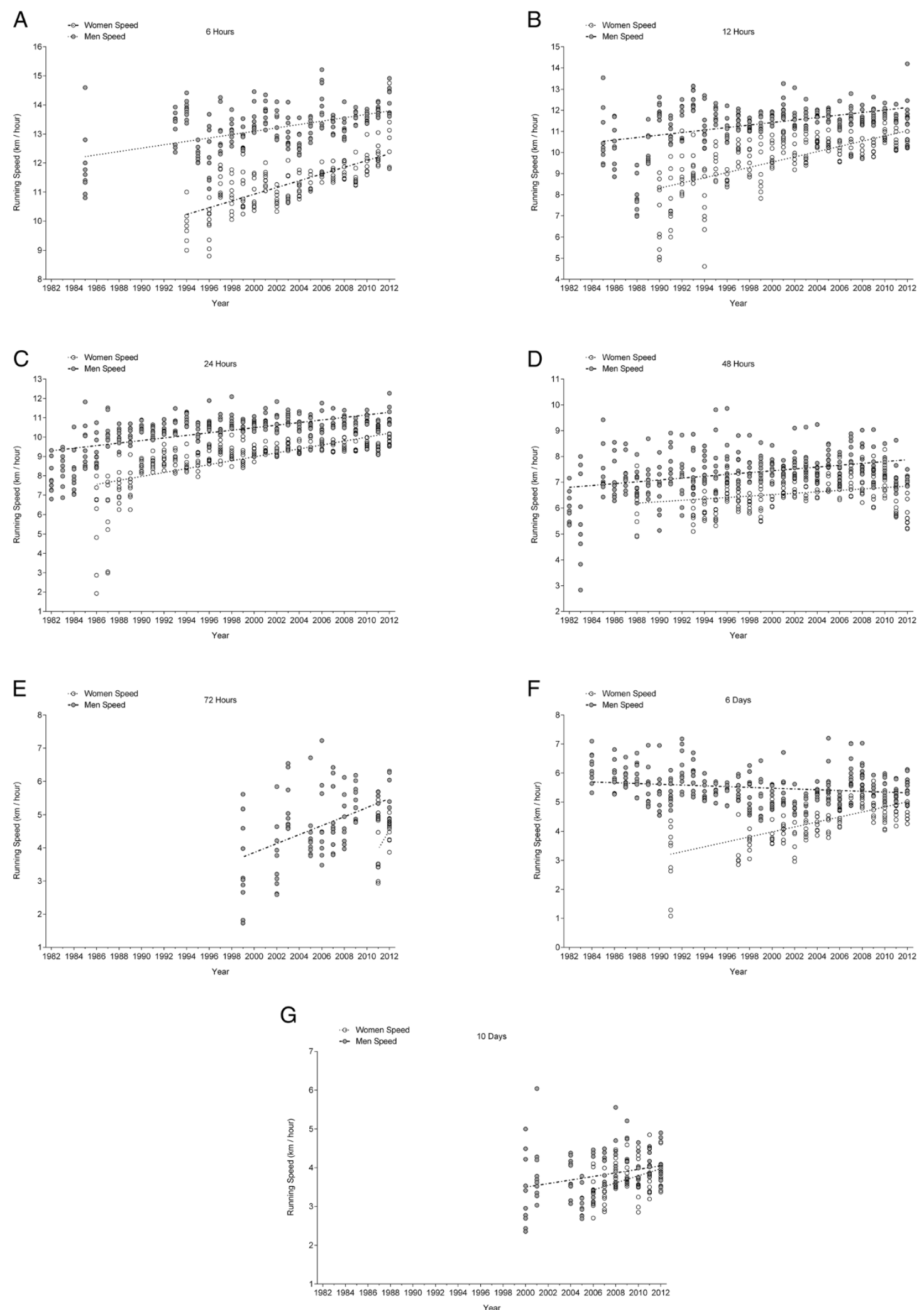

Figure 7 Changes in running speeds of the annual ten fastest women and men across the years in 6 hrs (Panel A), 12 hrs (Panel B), 24 hrs (Panel C), 48 hrs (Panel D), 72 hrs (Panel E), 6 d (Panel F) and $10 \mathrm{~d}$ (Panel G). 
Table 8 Multi-level regression analyses for the change in running speed across years for the annual ten fastest male and female runners after correction for multiple finishes and age of athletes with multiple finishes

\begin{tabular}{|c|c|c|c|c|c|}
\hline & B & SE (ß) & Stand. B & $\mathrm{T}$ & $p$ \\
\hline \multicolumn{6}{|c|}{ Annual ten fastest men } \\
\hline $6 \mathrm{hrs}$ & 0.060 & 0.007 & 0.534 & 9.034 & $<0.0001 *$ \\
\hline 12 hrs & 0.061 & 0.007 & 0.472 & 8.840 & $<0.0001 *$ \\
\hline 24 hrs & 0.067 & 0.005 & 0.633 & 14.344 & $<0.0001 *$ \\
\hline 48 hrs & 0.034 & 0.006 & 0.344 & 5.970 & $<0.0001 *$ \\
\hline 72 hrs & 0.136 & 0.024 & 0.503 & 5.721 & $<0.0001 *$ \\
\hline $6 \mathrm{~d}$ & -0.014 & 0.004 & -0.199 & -3.295 & $0.001 *$ \\
\hline $10 \mathrm{~d}$ & 0.044 & 0.016 & 0.260 & 2.773 & $0.007 *$ \\
\hline \multicolumn{6}{|c|}{ Annual ten fastest women } \\
\hline $6 \mathrm{hrs}$ & 0.116 & 0.009 & 0.700 & 13.087 & $<0.0001 *$ \\
\hline 12 hrs & 0.125 & 0.010 & 0.658 & 13.013 & $<0.0001 *$ \\
\hline $24 \mathrm{hrs}$ & 0.103 & 0.007 & 0.685 & 15.225 & $<0.0001 *$ \\
\hline 48 hrs & 0.023 & 0.007 & 0.215 & 3.148 & $0.002 *$ \\
\hline 72 hrs & 0.565 & 0.259 & 0.397 & 2.183 & $0.043 *$ \\
\hline $6 \mathrm{~d}$ & 0.087 & 0.009 & 0.620 & 10.117 & $<0.0001 *$ \\
\hline $10 \mathrm{~d}$ & 0.095 & 0.028 & 0.381 & 3.445 & $0.001 *$ \\
\hline
\end{tabular}

* = significantly different.

\section{Ultra-marathoners improved their running performance}

Another important finding was that the fastest finishers improved running speed across years of competition in all races although they showed no change in the athlete's age of peak performance. Similar findings have been reported for the analysis of $161-\mathrm{km}$ ultra-marathoners competing worldwide where performance improved and the athlete's age of peak performance remained unchanged across years of competition [3]. The annual top ten performances improved in 161-km ultra-marathoners by $13.7 \%$ from 1998 to 2011 for women and by $14.5 \%$ for men [3]. The mean athlete's ages of the annual top ten fastest runners were $\sim 39$ yrs for women and $\sim 37$ yrs for men [3]. The athlete's age of peak running performance was not different between women and men and showed no changes across years of competition [3].

The present findings differ, however, from results reported by Hoffman et al. [22] investigating performance trends in 161-km ultra-marathons held in North America between 1977 and 2008. The average race times of the fastest runners showed no change across years of competition for any age group for either sex. The different findings between the present study and the study of Hoffman et al. [22] might be explained by the different samples. While Hoffman et al. [22] investigated 161-km ultra-marathons held within one continent (North America) we investigated the total of all time-limited races held worldwide.

This finding for ultra-marathoners is in contrast to recent findings in triathletes competing in 'Ironman Hawaii' where the athlete's age in the annual top ten finishers increased although the athletes became faster 1983 and 2012 [27]. However, this trend could be confirmed in long-distance triathletes competing in 'Ultraman Hawaii' where the annual top three women and men improved their performance during the 1983-2012 period although the athlete's age of the annual top three women and men increased [28].

Similar findings of an increase of the athlete's age of peak athletic performance with rising race distance have been reported for swimmers [29-31] and triathletes [32-34]. In elite pool swimmers, men ( 24 yrs $)$ achieved peak performance

Table 9 Running speed of the annual ten fastest finishers in races held between 6 hours and 10 days

\begin{tabular}{|c|c|c|c|}
\hline Race & Sex & $\begin{array}{l}\text { Running speed of the runners at the } \\
\text { start of the investigated period }(\mathrm{km} / \mathrm{h})\end{array}$ & $\begin{array}{l}\text { Running speed of the runners at the } \\
\text { end of the investigated period }(\mathrm{km} / \mathrm{h})\end{array}$ \\
\hline \multirow[t]{2}{*}{$6 \mathrm{hrs}$} & Women & $9.93 \pm 0.54(1994)$ & $12.72 \pm 0.98$ (2012) \\
\hline & Men & $11.80 \pm 1.16(1985)$ & $14.10 \pm 0.47$ (2012) \\
\hline \multirow[t]{2}{*}{$12 \mathrm{hrs}$} & Women & $6.94 \pm 1.60(1990)$ & $10.44 \pm 0.25$ (2012) \\
\hline & Men & $10.71 \pm 1.30(1985)$ & $11.98 \pm 0.84$ (2012) \\
\hline \multirow[t]{2}{*}{$24 \mathrm{hrs}$} & Women & $6.23 \pm 2.34(1986)$ & $9.81 \pm 0.25(2012)$ \\
\hline & Men & $7.86 \pm 0.81(1986)$ & $11.07 \pm 0.51$ (2012) \\
\hline \multirow[t]{2}{*}{$48 \mathrm{hrs}$} & Women & $6.27 \pm 0.96(1988)$ & $7.09 \pm 0.60(2012)$ \\
\hline & Men & $6.02 \pm 0.58(1982)$ & $7.09 \pm 0.20(2012)$ \\
\hline \multirow[t]{2}{*}{$72 \mathrm{hrs}$} & Women & $3.96 \pm 0.91(2011)$ & $4.53 \pm 0.34(2012)$ \\
\hline & Men & $3.46 \pm 1.33(1999)$ & $5.33 \pm 0.64(2012)$ \\
\hline \multirow[t]{2}{*}{$6 \mathrm{~d}$} & Women & $3.22 \pm 1.28(1991)$ & $4.69 \pm 0.27(2012)$ \\
\hline & Men & $6.18 \pm 0.53(1984)$ & $5.66 \pm 0.28(2012)$ \\
\hline \multirow[t]{2}{*}{$10 d$} & Women & $3.45 \pm 0.43(2006)$ & $3.97 \pm 0.43(2012)$ \\
\hline & Men & $3.38 \pm 0.92(2000)$ & $3.94 \pm 0.51(2012)$ \\
\hline
\end{tabular}

Results are presented as mean \pm SD. 
later than women $(\sim 22 \mathrm{yrs})$ [29]. Similar athlete's ages of peak performance were reported for long-distance openwater swimmers [31]. In the $5 \mathrm{~km}, 10 \mathrm{~km}$ and $25 \mathrm{~km}$ FINA (Fédération Internationale de Natation) World Cup swimming events held from 2000 to 2012, the age of peak swimming speed remained stable at $\sim 22$ yrs in $5 \mathrm{~km}$, at $\sim 23 \mathrm{yrs}$ in $10 \mathrm{~km}$ and at $\sim 23 \mathrm{yrs}$ in $25 \mathrm{~km}$ for the annual top ten women [31]. For the annual top ten men, the athlete's age of peak swimming speed increased from $\sim 24$ to $\sim 28$ yrs in $10 \mathrm{~km}$ but remained stable at $\sim 25 \mathrm{yrs}$ in $5 \mathrm{~km}$ and at $\sim 27 \mathrm{yrs}$ in $25 \mathrm{~km}$ [31]. Older athlete's ages, however, were reported for open-water ultra-distance swimmers in longer race distances [30]. At the 46- $\mathrm{km}$ 'Manhattan Island Marathon Swim', the athlete's age of the annual three fastest swimmers increased from $\sim 28$ yrs (1983) to $\sim 38$ yrs (2013) in women and from $\sim 23$ yrs (1984) to $\sim 42$ yrs (2013) in men [30]. For Olympic distance triathletes (i.e. $1.5 \mathrm{~km}$ swimming, $40 \mathrm{~km}$ cycling and $10 \mathrm{~km}$ running), the athlete's ages of peak performance were similar $(\sim 28 \mathrm{yrs})$ for men and women [33]. In long-distance triathlon, however, it seemed that the athlete's age of peak performance increased with rising race distance [32,34]. For the Ironman distance (i.e. $3.8 \mathrm{~km}$ swimming, $180 \mathrm{~km}$ cycling and $42 \mathrm{~km}$ running), the athlete's age of peak Ironman triathlon performance was $\sim 32$ yrs for men and $\sim 33$ yrs for women [34]. For the Triple Iron ultra-triathlon distance (i.e. $11.4 \mathrm{~km}$ swimming, $540 \mathrm{~km}$ cycling and $126.6 \mathrm{~km}$ running), the mean athlete's age of the fastest male finishers was $\sim 38$ yrs and increased to 41 yrs for athletes competing in a Deca Iron ultratriathlon (i.e. $38 \mathrm{~km}$ swimming, 1,800 km cycling and $422 \mathrm{~km}$ running) [32].

\section{Limitations}

The results may not apply to distance limited races, such as 50-mile and especially 100-mile ultra-marathons that are often on trails with significantly more elevation gain and loss than time-limited event. The top finishers in difficult 100-mile trail ultramarathons are now frequently in their 20's [35-37].

\section{Conclusion}

The present findings show that for the fastest women ever in time-limited race between 1975 and 2012, the lowest age was in $10 \mathrm{~d}(\sim 37 \mathrm{yrs})$ and highest in $48 \mathrm{hrs}(\sim 46 \mathrm{yrs})$. For men, the athlete's age of the ten fastest in $6 \mathrm{hrs}(\sim 35 \mathrm{yrs})$ and 12 hrs ( $\sim 37$ yrs) was lower than the athlete's age of the ten fastest in $72 \mathrm{hrs}(\sim 48 \mathrm{yrs}), 6 \mathrm{~d}(\sim 48 \mathrm{yrs})$ and $10 \mathrm{~d}$ ( 48 yrs). The assumption that the age of peak ultramarathon performance increased with increasing race distance could not be confirmed. Although these athletes were master runners by definition, they improved their performance across years of competition. The differences in the athlete's age of peak performance between the sexes for the different race durations need further investigations.
Future studies are required to understand the motivation of master ultra-runners and to examine their specific training, physiology and anthropometric characteristics.

\section{Competing interests}

The authors declare that they have no competing interests.

\section{Authors' contributions}

CR performed the statistical analyses and drafted the manuscript, BK and MZ collected the data and helped in drafting the manuscript, TR helped in drafting the manuscript. All authors read and approved the final manuscript.

\section{Author details}

${ }^{1}$ Institute of Primary Care, University of Zurich, Zurich, Switzerland. ${ }^{2}$ Gesundheitszentrum St. Gallen, St. Gallen, Switzerland. ${ }^{3}$ Facharzt FMH für Allgemeinmedizin, Gesundheitszentrum St. Gallen, Vadianstrasse 26, 9001 St. Gallen, Switzerland.

Received: 29 June 2014 Accepted: 22 September 2014 Published: 27 September 2014

\section{References}

1. Cejka N, Rüst CA, Lepers R, Onywera V, Rosemann T, Knechtle B: Participation and performance trends in 100-km ultra-marathons worldwide. J Sports Sci 2014, 32:354-366.

2. Hoffman MD, Wegelin JA: The Western States 100-Mile Endurance Run: participation and performance trends. Med Sci Sports Exerc 2009, 41:2191-2198

3. Rüst CA, Knechtle B, Rosemann T, Lepers R: Analysis of performance and age of the fastest 100-mile ultra-marathoners worldwide. Clinics (Sao Paulo) 2013, 68:605-611.

4. Ultrarunnnig. website http://www.ultrarunning.com/.

5. Hunter SK, Stevens AA, Magennis K, Skelton KW, Fauth M: Is there a sex difference in the age of elite marathon runners? Med Sci Sports Exerc 2011, 43:656-664.

6. Cejka N, Knechtle B, Rüst CA, Rosemann T, Lepers R: Performance and age of the fastest female and male 100-km ultra-marathoners worldwide from 1960 to 2012. J Strength Cond Res 2014b, [Epub ahead of print].

7. Da Fonseca-Engelhardt K, Knechtle B, Rüst CA, Knechtle P, Lepers R, Rosemann T: Participation and performance trends in ultra-endurance running races under extreme conditions - 'Spartathlon' versus 'Badwater'. Extrem Physiol Med 2013, 2:15.

8. Knechtle B, Rüst CA, Rosemann T, Lepers R: Age-related changes in 100km ultra-marathon running performance. Age (Dordr) 2012, 34:1033-1045.

9. Zingg M, Rüst CA, Lepers $R$, Rosemann $T$, Knechtle B: Master runners dominate 24-h ultramarathons worldwide-a retrospective data analysis from 1998 to 2011. Extrem Physiol Med 2013, 2:21.

10. Zingg MA, Knechtle B, Rüst CA, Rosemann T, Lepers R: Analysis of participation and performance in athletes by age group in ultramarathons of more than 200 km in length. Int J Gen Med 2013, 6:209-220.

11. Zingg MA, Rüst CA, Rosemann $T$, Lepers $R$, Knechtle B: Runners in their forties dominate ultra-marathons from 50 to 3,100 miles. Clinics (SaO Paulo) 2014, 69:203-211.

12. Ultramarathon Running Resource. website http://www.ultramarathonrunning. $\mathrm{com} /$.

13. Deutsche Ultramarathon Vereinigung (DUV). website http://www.ultramarathon.org/.

14. Deutsche Ultramarathon Vereinigung (DUV). website http://statistik.d-u-v.org.

15. Knoth C, Knechtle B, Rüst CA, Rosemann T, Lepers R: Participation and performance trends in multistage ultramarathons-the 'Marathon des Sables' 2003-2012. Extrem Physiol Med 2012, 1:13.

16. Peter L, Rüst CA, Knechtle B, Rosemann $T$, Lepers R: Sex differences in 24-hour ultra-marathon performance-a retrospective data analysis from 1977 to 2012. Clinics (Sao Paulo) 2014, 69:38-46.

17. Ruiz-Juan F, Zarauz A: Predictor variables of motivation on Spanish master athletes. J Hum Sport Exerc 2012, 7:617-628.

18. Krouse RZ, Ransdell LB, Lucas SM, Pritchard ME: Motivation, goal orientation, coaching, and training habits of women ultrarunners. J Strength Cond Res 2011, 25:2835-2842. 
19. Deaner RO: Distance running as an ideal domain for showing a sex difference in competitiveness. Arch Sex Behav 2013, 42:413-428.

20. Knechtle B: Ultramarathon runners: nature or nurture? Int I Sports Physiol Perform 2012, 7:310-312.

21. Hoffman MD, Parise CA: Longitudinal assessment of age and experience on performance in 161-km ultramarathons. Int I Sports Physiol Perform 2014, [Epub ahead of print].

22. Hoffman MD, Ong JC, Wang G: Historical analysis of participation in $161 \mathrm{~km}$ ultramarathons in North America. Int J Hist Sport 2010, 27:1877-1891.

23. Hoffman MD, Krishnan E: Exercise behavior of ultramarathon runners: baseline findings from the ULTRA Study. I Strength Cond Res 2013, 27:2939-2945.

24. Hoffman MD: Performance trends in 161-km ultramarathons. Int J Sports Med 2010, 31:31-37.

25. Hoffman MD, Fogard K: Demographic characteristics of $161-\mathrm{km}$ ultramarathon runners. Res Sports Med 2012, 20:59-69.

26. Wegelin JA, Hoffman MD: Variables associated with odds of finishing and finish time in a 161-km ultramarathon. Eur J App/ Physiol 2011, 111:145-153.

27. Gallmann D, Knechtle B, Rüst CA, Rosemann T, Lepers R: Elite triathletes in 'Ironman Hawaii' get older but faster. Age (Dordr) 2014, 36:407-416.

28. Meili D, Knechtle B, Rüst CA, Rosemann T, Lepers R: Participation and performance trends in 'Ultraman Hawaii' from 1983 to 2012. Extrem Physiol Med 2013, 2:25.

29. Allen SV, Vandenbogaerde TJ, Hopkins WG: Career performance trajectories of Olympic swimmers: Benchmarks for talent development. Eur J Sport Sci 2014, [Epub ahead of print].

30. Knechtle B, Rosemann T, Lepers R, Rüst CA: Women outperform men in ultra-distance swimming - the 'Manhattan Island Marathon Swim' from 1983 to 2013. Int I Sports Physiol Perform 2014, [Epub ahead of print].

31. Zingg MA, Rüst CA, Rosemann T, Lepers R, Knechtle B: Analysis of swimming performance in FINA World Cup long-distance open water races. Extrem Physiol Med 2014, 3:2.

32. Knechtle B, Rüst CA, Knechtle $P$, Rosemann T, Lepers R: Age-related changes in ultra-triathlon performances. Extrem Physiol Med 2012, 1:5.

33. Malcata RM, Hopkins WG, Pearson SN: Tracking career performance of successful triathletes. Med Sci Sports Exerc 2014, 46:1227-1234.

34. Stiefel M, Knechtle B, Rüst CA, Rosemann T, Lepers R: The age of peak performance in Ironman triathlon: a cross-sectional and longitudinal data analysis. Extrem Physiol Med 2013, 2:27.

35. The Barkley Marathons - 100 Mile Run. website www.mattmahoney.net/ barkley.

36. Hardrock Hundred Endurance Run. website http://hardrock100.com.

37. Leadville Trail 100 Run. website www.leadvilleraceseries.com.

doi:10.1186/2052-1847-6-36

Cite this article as: Rüst et al.: Will the age of peak ultra-marathon

performance increase with increasing race duration? BMC Sports Science, Medicine and Rehabilitation 2014 6:36.

\section{Submit your next manuscript to BioMed Central and take full advantage of:}

- Convenient online submission

- Thorough peer review

- No space constraints or color figure charges

- Immediate publication on acceptance

- Inclusion in PubMed, CAS, Scopus and Google Scholar

- Research which is freely available for redistribution

Submit your manuscript at www.biomedcentral.com/submit
C Biomed Central 